\title{
Evaluation of Taline-1, MCP-1 and IGF-1 in Prediction the Risk of Developing Hepatocellular Carcinoma in Patients With Liver Cirrhosis
}

\author{
Seham A Khodeer ${ }^{1}$, Azza M Abdu Allah ${ }^{2}$, Hany R Alwakeel ${ }^{3}$, Eman Abd El- \\ Razek $^{4}$, Ahmed Abd Elrahman ${ }^{5}$ \\ ${ }^{I}$ Seham A Khodeer, MD, Assistant Professor of Clinical Pathology, Clinical Pathology Department, Faculty of \\ Medicine, Menoufia University, Egypt. \\ ${ }^{2}$ Azza M Abdu Allah, MD, Assistant Professor of Biochemistry, Biochemistry Department, Faculty of Medicine, \\ Menoufia University, Egypt \\ ${ }^{3}$ Hany R Alwakeel, Assistant Professor, Hepatology Department, National Liver Institute, Menoufia University, \\ Egypt. \\ ${ }^{4}$ Eman Abd El-Razek MD, Assistant Professor, Oncology Department, Oncology Institute, Faculty of Medicine, \\ Menoufia University, Egypt. \\ ${ }^{5}$ Ahmed Khaled Abd Elrahman, Medical student, Faculty of Medicine, Menoufia University, Egypt
}

\begin{abstract}
Background: Hepatocellular carcinoma (HCC) is the third most common cause of cancer mortality worldwide. Oncologists depend on AFP as the commonest and feasible marker for assessing HCC in addition to imaging. However, AFP is not completely a reliable marker in early HCC diagnosis due to its low specificity and sensitivity.

Objective: evaluation of serum levels of monocyte chemo attractant protein-1 (MCP-1), talin-1\& insulin like growth factor-1(IGF-1) in Egyptian patients with HCC compared to liver cirrhosis \& healthy controls and to find their values in HCC prediction.

Subjects and methods: Subjects sharing were classified as follows: 25 patients with liver cirrhosis, 39 patients suffering from HCC on top of liver cirrhosis in addition to 24 apparently healthy subjects as control group. They were subjected to complete physical examination, routine biochemical tests, radiological examination, serum AFP, taline-1, MCP-1 \& IGF-1 determinations.

Results: high significant increases in the serum level of talin-1 in HCC patients in comparison with both cirrhotic and control groups. Also, there was a high significant increase in cirrhotic patients compared with the controls. Serum MCP-1 levels were significantly higher in the HCC group than in the cirrhotic group or the controls. However, no significant difference was found between cirrhotic and control groups.the highest sensitivity for detection of HCC was in the favor of MCP-1 (100\%), while the highest specificity was taline$1(100 \%)$.

Conclusion: our findings support the potential role of MCP-1 \& taline-1 in as screening markers for HCC in cirrhotic patients. The early detection of HCC and discrimination of malignant from the cirrhotic cases is a challenge for the oncologists so, continuous and regular monitoring systems using MCP-1 or the combination of taline-1 with AFP could improve the diagnostic performance over AFP alone in the early detection of HCC in patients with liver cirrhosis.
\end{abstract}

Keywords: hepatocellular carcinoma - Monocyte Chemoattractant Protein-1. taline-1 - insulin like growth factor -1 .

\section{Introduction}

Hepatocellular carcinoma (HCC) is the third most common cause of cancer mortality worldwide (1) In Egypt, the incidence rate of HCC was doubled in the past 10 years (2) It contributes to $14.8 \%$ of all cancer mortality in Egypt, with a higher incidence in males than in females. It is the second most frequent cancer type in Egyptian males and the eighth most frequent in Egyptian females (3) Liver cirrhosis is one of the underlying liver diseases that put patients at risk for the development of HCC (4). Emerging data indicate that the mortality rate of $\mathrm{HCC}$ associated with cirrhosis is rising in some developed countries, whereas mortality from non-HCC complications of cirrhosis is decreasing or is stable (5) HCC is usually asymptomatic in the early stages and tends to be invasive in late stages. Therefore, most patients present with an incurable disease at the time of detection, which makes early diagnosis of HCC critical for a good prognosis (6). Most imaging techniques help to discover HCC after considerable time of onset of tumor. In most instances, oncologists depend on AFP as the commonest and feasible marker for assessing $\mathrm{HCC}$ in addition to imaging (3). 
However, AFP is not completely a reliable marker in early HCC diagnosis, prevention or therapy due to its low specificity and sensitivity. Liver biopsy is always considered as an invasive procedure, so chemical findings are still greatly appreciated (7) Talin-1 is a key adaptor protein that regulates integrin conformation and cell migration, and has been shown to play an important role in promoting tumor cell adhesion, migration and invasion in different types of cancer (8) monocyte chemoattractant protein-1(MCP-1) belongs to the family of chemotactic cytokines known as chemokines, was found to be secreted by mononuclear cells and various nonleukocytic cells (9). Migration of monocytes from the blood stream across the vascular endothelium is required for routine immunological surveillance of tissues, as well as in response to inflammation (10). It has been demonstrated that MCP-1-mediated macrophage infiltration promotes tumor progression in various types of cancer (11).

Insulin-like growth factor 1 (IGF-1) is a protein produced primarily by the liver as an endocrine hormone as well as in target tissues in a paracrine/ autocrine fashion (3) IGF-1 potent survival factor and implicated in the development and progression of various cancers (12)

Aim of the work: Evaluation of serum levels of monocyte chemoattractant protein-1 (MCP-1), talin-1\& insulin like growth factor-1(IGF-1) in Egyptian patients with HCC compared to liver cirrhosis\& healthy controls and to find their values in $\mathrm{HCC}$ prediction.

\section{Subjects and Methods:}

This study was carried out at Clinical Pathology, Medical Biochemistery Departments and Oncology Institute, Faculty of Medicine, in collaboration with Hepatology Department, National Liver Institute, Menoufia University, in the duration between June 2013 and June 2016.

\section{I-Subjects:}

The study included 64 patients from those attending the Outpatient Clinic and inpatients of Hepatology Department of National Liver Institute and Oncology Institute. They were classified as follow: 25 patients with liver cirrhosis, 39 patients suffering from HCC on top of liver cirrhosis. In addition to 24 apparently healthy age and gender matched- subjects considered as the control group. All individuals were subjected to complete physical examination, routine biochemical tests, serum AFP, taline-1, MCP-1 \& IGF-1 determinations and abdominal ultrasonography. Patients with liver cirrhosis were diagnosed by clinical \& biochemical examinations, ultrasonography and computerized tomography. Patients with HCC were diagnosed by triphasic CT.

The study design was accepted by the local Ethics Committee. Informed consents were obtained from the shared subjects. Any patient with cardiac, respiratory or renal dysfunction was excluded. Diabetic patients, patients with evidence of recent systemic infection or active variceal bleeding, hepatic encephalopathy or spontaneous bacterial peritonitis were also excluded. None of the control group was suffering from any other medical conditions.

\section{- Sampling.}

\section{Methods}

Samples are taken under complete aseptic conditions, after an overnight fasting ; $7 \mathrm{ml}$ venous blood sample of all subjects were taken and collected in a sterile tube, allowed to clot and centrifuged at $3000 \mathrm{rpm}$ for 15 minutes for separating the serum to assess ALT, AST, ALP, total and direct bilirubin, creatinine and BUN. The residual serum were divided in 4 aliquots and stored at $-20 \mathrm{C}$ for measuring of AFP, IGF-I, MCP-1\& taline-1

\section{- Laboratory methods:}

Biochemical tests for detection of liver function were done on Synchron CX9 autoanalyser using kit supplied by Beckman (Beckman Instrument. Inc.Fullerton, California USA). Hepatitis viral markers (HBsAg and HCV Ab) done by "ECLIA" using Cobas 411 analyzers ( Roche diagnostics,Germany).Serum Talin-1 MCP-1, IGF-1 and AFP using enzyme linked immunesorbent assay (ELISA) Serum Talin-1 assayed by using enzyme linked immunesorbent assay (ELISA) which supplied by WKEA MED SUPPLIES CORP, NEW YORK, USA. The assay kit measures human Talin-1 level in serum samples using purified human Talin antibody to coat microtiter plate wells and make solid-phase antibody, then addition of Talin to wells, combined Talin which with enzyme labeled, become antibody-antigen-enzyme-antibody complex, after complete washing, substrate is added, substrate becomes blue color which is HRP enzyme-catalyzed reaction. This reaction is terminated by addition of sulphuric acid solution and the color changes to yellow and its intensity is measured spectrophotometrically at a wavelength of $450 \mathrm{~nm}$. The concentration of Talin in the samples is then determined by comparing the O.D. of the samples to the standard curve. MCP-1 level assayed by ELISA kit supplied by WKEA MED SUPPLIES CORP( NEW YORK, USA) by using purified human MCP-1 antibody to coat microtiter plate wells and make solid-phase antibody, then addition of MCP-1 to wells, combined MCP-1 which with enzyme labeled, become antibody-antigen-enzyme-antibody complex, after complete washing, 
substrate is added, substrate becomes blue color which is HRP enzyme-catalyzed reaction. This reaction is terminated by addition of sulphuric acid solution and the color changes to yellow and its intensity is measured spectrophotometrically at a wavelength of $450 \mathrm{~nm}$. The concentration of MCP-1 in the samples is then determined by comparing the O.D. of the samples to the standard curve.IGF-1: level in could be assayed by Abcam's IGF1 Human ELISA kit (UK, EU and ROW Email: technical@abcam.com). This assay employs an antibody specific for Human IGF1 coated on a 96-well plate. Standards and samples are pipetted into the wells and IGF1 present in a sample is bound to the wells by the immobilized antibody. The wells are washed and biotinylated anti-Human IGF1 antibody is added. After washing away unbound biotinylated antibody, HRPconjugated streptavidin is pipetted to the wells. The wells are again washed, a TMB substrate solution is added to the wells and color develops in proportion to the amount of IGF1 bound. The Stop Solution changes the color from blue to yellow, and the intensity of the color is measured at $450 \mathrm{~nm}$

\section{Analytic statistics}

The statistical analysis was undertaken using SPSS software (version 17; SPSS Inc., Chicago, IL, USA). Descriptive statistics in the form of mean and standard deviation for parametric data were used. Chisquare test $\left(\chi^{2}\right)$ was used for two qualitative variables. Kruskal-Wallis test for comparison between three groups not normally distributed having quantitative variables, followed by LSD (least significant difference. Pearson correlation coefficient (r) used to test correlation between two quantitative variables.diagnostic sensitivity , specificity , positive predictive value (PPV), negative predictive value (NPV), diagnostic accuracy and Receiver Operator Characteristic Curve (ROC) a graphic representation of the relationship between sensitivity and specificity at different cut-off points for a diagnostic test The significance level was set at 0.05 .

\section{Results:}

Results are explained in tables,

\section{Discussion}

The serum alpha-fetoprotein (AFP) is the most commonly used HCC biomarker, However, its poor sensitivity and specificity renders it unsatisfactory for this purpose. The prognosis of HCC is very difficult which necessitates finding of new appropriate either single or panel serum markers that could be used for early detection of HCC in high risk patients like patients with liver cirrhosis (13)

Taline-1 is a large cytoskeletal dimeric adaptor protein that associates with the integrin family of cell adhesion molecules in cell extracellular matrix junctions where it both activates integrins and couples them to the actin cytoskeleton (14) The current study showed high significant increases in the serum level of talin-1 in HCC patients in comparison with both cirrhotic and control groups. Also, there was a high significant increase in cirrhotic patients compared with the controls. These results are similar to that of Youns et al.,[15] who found that serum talin-1 levels were significantly higher in the HCC group than in the liver cirrhosis group and controls. Moreover, (14)Kanamori et al.,reported that talin-1 expression levels in HCC nodules identified by differential tissue proteome were significantly associated with undifferentiated HCC and showed correlation between talin-1 upregulation and a shorter time to recurrence after resection. In addition, Fang et al., [16] reported that high levels of talin-1 expression is correlated with tumorigenicity in human HCC, indicating that these molecules constitute important molecular targets for the diagnosis and/or treatment of HCC. On the other hand, (17) Zhang et al. have proved that taline-1 is down-regulated in HCC liver tissues when compared with adjacent non-cancerous liver tissues or with control liver tissues by immuno- histochemistry and real time PCR .

By using pearsons correlation in patients with $\mathrm{HCC}$, only a positive correlation was found between taline-1 and AFP. Meanwhile, no correlations were found between taline-1 and other studied parameters. (15)Youns et al., found no significant correlations between taline-1 and other biochemical variables in patients with HCC.In the current study and by using ROC curve, the best cutoff of talin-1 that can discriminate HCC patients from cirrhotic was at $17.24 \mathrm{ng} / \mathrm{ml}$ with a sensitivity of $97 \%$, specificity of $100 \%$ and diagnostic accuracy of $96 \%$. Moreover, ROC curve analysis showed AUC for taline-1 was higher than that of AFP (sensitivity of $95 \%$, specificity of $80 \%$ ). Parallel combination of AFP and taline-1 raise the sensitivity and specificity up to $100 \%$ and $84 \%$, respectively. Our results were in agreement with Youns et al., [15] who studied the diagnostic utility of talin-l in diagnosis of HCC, they found that at acutoff value of $33.7 \mathrm{ng} / \mathrm{ml}$ the diagnostic sensitivity was $100 \%$ and specificity $87 \%$. ROC curve analysis showed AUC for taline-1 was higher than that of AFP alone or in combination with taline.

MCP-1 is a member of the small inducible gene family, and plays a role in the recruitment of monocytes to sites of injury and infection, its expression may plausibly be associated with HCC development (18). The current study showed a highly significant increase in the serum level of MCP-1 in HCC patients in comparison with other groups. The results are similar to that of Wang et al., (19) who found that serum MCP-1 levels were significantly higher in the HCC group than in the cirrhotic group or the controls. However, our rsults revealed that no statistical significant difference was found between patints with liver cirrhosis and the 
control group. Meanwhile, Camps et al., (20) found that there was a significant increase in level of MCP-1 in patients with all grades of hepatic affection in comparison to controls. The association between MCP-1 and liver damage has been implied due to the findings that specific non-malignant cells are major source of $\mathrm{MCP}-1$, such as the hepatic stellate cells that are known to be involved in the development of fibrosis and cirrhosis [21], [22]. Meanwhile, and in coressponding to our results, Lin et al., stated that in HCC, HCC cells and cancer-associated fibroblasts are prominent contributors of MCP-1, regardless of whether the liver is cirrhotic (23).

By using pearsons correlation, MCP-1 was positively correlated with ALT/AST ratio. No correlations were found between the studied marker and the other parameters. Wang et al.,(19) found no significant correlation between MCP-1 and liver function tests. ROC curve analysis revealed that at a cutoff level of 52.0 ng/ml, MCP-1 can discriminate between HCC and cirrhotic patients with a sensitivity of $100 \%$ which was higher than both AFP and taline-1. The specificity of MCP-1 was $80 \%$ which equal to that of AFP and lower than that of taline-1. Parallel combination of AFP and MPC-1 only improve the sensitivity of AFP to reach $100 \%$. parallel combination of MCP-1 and taline-1add nothing to the value of sensitivity and specificity of MCP-1. These data suggested that serum level of MCP-1 could be used as a screening marker for early detection of HCC with a reasonable diagnostic accuracy.

IGF signaling system plays a pivotal role in the development and progression of various cancers ( 24). However, the relevance of IGF-I to hepatocellular carcinoma is somewhat different from other malignancies because the majority of circulating IGF-I is produced by the liver (25) .

The obtained results revealed the presence of significant decrease in cirrhotic and HCC patients comparing with the controls. Meanwhile, no statistical significant difference was found between the cirrhotic and HCC patient groups. the obtained data were near those obtaind by Su et al.,[26] who demonstrate that the development of HCC is accompanied by a significant reduction of serum IGF-I levels in comparison to healthy subjects which is also noted in chronic liver disease. To the opposite of our results, Aleem et al.,[3] reported that the reduction of IGF-1 levels was statistically significant between cirrhosis and HCC patients. As regarding the decrease in IGF-1 in cirrhotic patients than healthy subjects many studies contribute this decrease to affection of liver parenchyma that reduce synthetic capability of damaged hepatocytes because hepatocytes are the main contributors of circulating IGF.The present study showed that there were significant positive correlations between IGF-1 level and total protein, albumin and MCP-1. Meanwhile, no correlation was observed with other variables including taline-1. By using ROC curve analysis the diagnostic accuracy of IGF-1 in the early detection of HCC was poor as AUC was in the range 57.4 with a sensitivity of $51 \%$ and specificity of $20 \%$

\section{Conclusion}

Our findings support the potential role of MCP-1 \& taline-1 in as screening markers for HCC in cirrhotic patients. The early detection of HCC and discrimination of malignant from the cirrhotic cases is a challenge for the oncologists so, continuous and regular monitoring systems using MCP-1 or the combination of taline-1 with AFP could improve the diagnostic performance over AFP alone in the early detection of HCC in patients with liver cirrhosis. The cost benefit should be put in consideration to determine how far using these markers could improve the chances for early detection of HCC in patients at risk- as those with liver cirrhosiscould improve their prognosis and survival rate.

\section{References}

[1]. Hsieh PM, Hung KC, Chen YS ( 2009): Tumor lysis syndrome after transarterial chemoembolization of hepatocellular carcinoma: case reports and literature review.World J Gastroenterol.;15:4726-4728.

[2]. Abdelaziz AO, Elbaz TM, Shousha HI, et al (2014): Survival and prognostic factors for hepatocellular carcinoma: an Egyptian multidisciplinary clinic experience.Asian Pac J Cancer Prev, 15,3915-20.

[3]. Aleem E, Elshayeb A, Elhabachi N, Mansour A, Gowily A, And Helal A (2012) :Serum IGFBP-3 is a more effective predictor than IGF-1 and IGF-2 for the development of hepatocellular carcinoma in patients with chronic HCV infection. Oncol Lett.; 3(3): 704-712.

[4]. Sherman M (2010): Hepatocellular carcinoma: New and emerging risks.Digestive and Liver Disease. 42,( 3),: 215-222.

[5]. Giovanna Fattovich, Tommaso Stroffolini, Irene Zagni, Francesco Donato (2004): Hepatocellular carcinoma in cirrhosis: Incidence and risk factors . Gastroenterology, 127(5) :35-S50.

[6]. Song P, Gao J, , Kokudo N (2014): Serum biomarkers for early diagnosis of hepatocellular carcinomaHepatocellularCaricinoma Column Home ., 3( 2) :35-38

[7]. Rauf AA, El-Sebaa HM, El-Shafie MK, El-Fert AY, Ghanem SE (2014): Interleukin $1 \beta$ and metalloproteinase 3 gene polymorphisms in hepatocellular carcinoma patients in Egypt. Menoufia Medical ; 27 ( 3 ): 594-601. 
[8]. Fang KP1, Dai W2, Ren YH3, Xu YC4, Zhang SM5, Qian YB6,7.(2016):Both Talin-1 and Talin-2 correlate with malignancy potential of the human hepatocellular carcinoma MHCC-97 L cell. 28;16(1):45

[9]. Hinojosa AE, Garcia BB, Leza JC, et alCCL2/MCP-1(2011): modulation of microglial activation and proliferation. J Neuroinflammation.; 88:77.

[10]. Deshmane S L,Kremlev S, Amini S, and Sawaya B E (2009): Monocyte Chemoattractant Protein-1 (MCP-1)An OverviewJ Interferon Cytokine Res. ; 29(6): 313-326.

[11]. Qian BZ, Li J, Zhang H, Kitamura T, Zhang J, et al. (2011): CCL2 recruits inflammatory monocytes to facilitate breast-tumour metastasis. Nature; 475: 222-225.

[12]. Cho E, Kim H, Lee J, Yoo J, Choi W, Cho Y, Lee M, Cho Y, Lee D, Lee Y, Yu S, Kim Y, Yoon J, Chung J, Kim C, and Suk H (2014): Serum Insulin-Like Growth Factor-1 Predicts Disease Progression and Survival in Patients with Hepatocellular Carcinoma Who Undergo Transarterial Chemoembolization. Lee PLoS One. 2014; 9(3): e90862.

[13]. Zekri AR1, Youssef AS, Bakr YM, Gabr RM, El-Rouby MN, Hammad I, Ahmed EA, Marzouk HA, Nabil MM, Hamed HA, Aly YH, Zachariah KS, Esmat G (2015):Serum biomarkers for early detection of hepatocellular carcinoma associated with HCV infection in egyptian patients. Asian Pac J Cancer Prev.; 16(3):1281-7.

[14]. Kanamori H, Kawakami T, Effendi K, Yamazaki K, Mori T, Ebinuma H, et al.(2011): Identification by differential tissue proteome analysis of talin-1 as a novel molecular marker of progression of hepatocellular carcinoma.Oncology;80(5-6):406-15.

[15]. Youns MM, Abdel Wahab AH, Hassan ZA, Attia MS (2013): Serum talin-1 is a potential novel biomarker for diagnosis of hepatocellular carcinoma in Egyptian patients. Asian Pac J Cancer Prev.;14(6):3819-23.

[16]. Fang KP, Zhang JL, Ren YH, Qian YB.(2014): Talin-1 correlates with reduced invasion and migration in human hepatocellular carcinoma cells. Asian Pac J Cancer Prev. ;15(6):2655-61.

[17]. Zhang JL, Qian YB, Zhu LX, Xiong QR (2011).Talin1, a valuable marker for diagnosis and prognostic assessment of human hepatocelluar carcinomas.Asian Pac J Cancer Prev, 12, 3265-9.

[18]. Dagouassat M, Suffee N, Hlawaty H, Haddad O, Charni F, et al. (2010) Monocyte chemoattractant protein-1 (MCP-1)/CCL2 secreted by hepatic myofibroblasts promotes migration and invasion of human hepatoma cells. Int J Cancer 126: 1095-1108

[19]. Wang WW, Ang SF, Kumar R et al.,(2013): Identification of serum monocyte chemoattractant protein-1 and prolactin as potential tumor markers in hepatocellular carcinoma. PLOS One; 8: e68904.

[20]. Camps J, Marsillach J, Rull A et al., (2010): Interrelationships between paraoxonase-1 and monocyte chemoattractant protein-1 in the regulation of hepatic inflammation. AdvExp Med Biol ; 660:5-18.

[21]. Friedman SL (2000) Molecular regulation of hepatic fibrosis, an integrated cellular response to tissue injury. J Biol Chem 275: 2247-2250.

[22]. Marra F, DeFranco R, Grappone C, Milani S, Pastacaldi S, et al. (1998) Increased expression of monocyte chemotactic protein-1 during active hepatic fibrogenesis: correlation with monocyte infiltration. Am J Pathol 152: 423-430

[23]. Lin ZY, Chuang YH, Chuang WL (2012) Cancer-associated fibroblasts up-regulate CCL2, CCL26, IL6 and LOXL2 genes related to promotion of cancer progression in hepatocellular carcinoma cells. Biomed Pharmacother 66: 525-529.

[24]. Pollak (2008): Insulin and insulin-like growth factor signalling in neoplasia. Nat Rev Cancer ;8:915-928

[25]. Mazziotti G, Sorvillo F, Morisco F, Carbone A, Rotondi M, Stornaiuolo G, et al. (2002) :Serum insulinlike growth factor I evaluation as a useful tool for predicting the risk of developing hepatocellular carcinoma in patients with hepatitis C virus-related cirrhosis: a prospective study. Cancer;95:2539-45.

[26]. Su w, Lee K, Yeh , et al., (2010) : association of circulating insulin like growth factor 1 wiyh hepatocellular carcinoma : one cross sectional correl;ation studey . journal of clinical laboratory analysis , 24:195-200. 
Table (1): Demographic criteria and laboratory investigations of the studied groups.

\begin{tabular}{|c|c|c|c|c|c|}
\hline \multirow{3}{*}{ Variable } & \multicolumn{3}{|l|}{ Groups } & \multirow{3}{*}{$\begin{array}{l}\text { Kruskal-Wallis } \\
\text { test }\end{array}$} & \multirow{3}{*}{ Post hoc value } \\
\hline & $\begin{array}{l}\text { Cirrhotic }^{(1)} \\
(\mathrm{N}=\mathbf{2 5})\end{array}$ & $\begin{array}{l}\mathrm{HCC}^{(\text {III }} \\
(\mathrm{N}=39)\end{array}$ & $\begin{array}{l}\text { Controls } \\
(\mathrm{N}=\mathbf{2 4})\end{array}$ & & \\
\hline & Mean \pm SD & Mean \pm SD & Mean \pm SD & & \\
\hline Age (year) & $53.54 \pm 10.49$ & $56.10 \pm 5.32$ & $54.75 \pm 6.13$ & $\begin{array}{l}\mathrm{F}=1.29 \\
\mathrm{P}=0.279\end{array}$ & $\begin{array}{r}\text { I vs. II }=0.112 \\
\text { vs. III }=0.428 \\
\text { II vs. } I I I=0.480\end{array}$ \\
\hline Male/Female & $20 / 5$ & $30 / 9$ & $14 / 10$ & $\begin{array}{l}\quad \chi^{2}=0.08 \\
\chi^{2}=2.70 \\
\chi^{2}=2.43\end{array}$ & $\begin{array}{l}\text { I vs. II }=0.771 \\
\text { I vs. } I I I=0.100 \\
\text { II vs. III }=0.118\end{array}$ \\
\hline AST (U/L) & $\begin{array}{l}44.28 \pm 42.53 \\
M=24.0\end{array}$ & $\begin{array}{l}99.20 \pm 85.57 \\
M=70.50\end{array}$ & $\begin{array}{l}15.24 \pm 3.53 \\
M=15.0\end{array}$ & $\begin{array}{l}52.89 \\
P<0.001(H S)\end{array}$ & $\begin{array}{l}\text { I vs. II }<0.001 \\
\text { I vs. III }<0.001 \\
\text { II vs. III }<0.001\end{array}$ \\
\hline ALT (U/L) & $\begin{array}{l}77.84 \pm 57.03 \\
M=52.0\end{array}$ & $\begin{array}{l}88.05 \pm 149.47 \\
M=55.50\end{array}$ & $\begin{array}{l}16.17 \pm 4.47 \\
M=16.0\end{array}$ & $\begin{array}{l}43.48 \\
P=0.001(\mathrm{HS})\end{array}$ & $\begin{array}{l}\text { I vs. II }=0.308 \\
\text { I vs. III }<0.001 \\
\text { II vs. III }<0.001\end{array}$ \\
\hline AST/ALT & $\begin{array}{l}0.57 \pm 0.22 \\
M=0.57\end{array}$ & $\begin{array}{l}1.61 \pm 0.82 \\
M=1.54\end{array}$ & $\begin{array}{l}0.98 \pm 0.22 \\
M=0.96\end{array}$ & $\begin{array}{l}46.53 \\
P<0.001(\mathrm{HS})\end{array}$ & $\begin{array}{l}\text { I vs. II }<0.001 \\
\text { I vs. III }<0.001 \\
\text { II vs. III }<0.001\end{array}$ \\
\hline $\operatorname{ALP}(\mathbf{U} / \mathbf{L})$ & $\begin{array}{l}110.56 \pm 80.25 \\
M=78.0\end{array}$ & $\begin{array}{l}127.15 \pm 53.87 \\
M=102.50\end{array}$ & $\begin{array}{l}64.22 \pm 10.57 \\
M=63.60\end{array}$ & $\begin{array}{l}29.49 \\
P<0.001(\mathrm{HS})\end{array}$ & $\begin{array}{l}\text { I vs. II }=0.034 \\
\text { I vs. III }=0.009 \\
\text { II vs. III }<0.001\end{array}$ \\
\hline$\square \mathbf{G T}(\mathbf{U} / \mathbf{L})$ & $\begin{array}{l}37.80 \pm 32.59 \\
M=29.0\end{array}$ & $\begin{array}{l}58.10 \pm 37.40 \\
M=40.50\end{array}$ & $\begin{array}{l}19.07 \pm 5.27 \\
M=19.0\end{array}$ & $\begin{array}{l}36.94 \\
P<0.001(H S)\end{array}$ & $\begin{array}{l}\text { I vs. II }=0.002 \\
\text { I vs. III }=0.009 \\
\text { II vs. III }<0.001\end{array}$ \\
\hline $\begin{array}{l}\text { Total Bilirubin } \\
\text { (mg/dl) }\end{array}$ & $\begin{array}{l}3.13 \pm 2.97 \\
M=1.75\end{array}$ & $\begin{array}{l}2.22 \pm 1.84 \\
M=1.55\end{array}$ & $\begin{array}{l}0.57 \pm 0.17 \\
M=0.55\end{array}$ & $\begin{array}{l}40.20 \\
P<0.001(H S)\end{array}$ & $\begin{array}{l}\text { I vs. II }=0.746 \\
\text { I vs. III }<0.001 \\
\text { II vs. III }<0.001\end{array}$ \\
\hline $\begin{array}{l}\text { Direct Bilirubin } \\
\text { (mg/dl) }\end{array}$ & $\begin{array}{l}1.90 \pm 2.15 \\
M=0.70\end{array}$ & $\begin{array}{l}1.18 \pm 1.25 \\
M=0.71\end{array}$ & $\begin{array}{l}0.11 \pm 0.4 \\
M=0.10\end{array}$ & $\begin{array}{l}44.91 \\
P<0.001(H S)\end{array}$ & $\begin{array}{l}\text { I vs. II }=0.731 \\
\text { I vs. III }<0.001 \\
\text { II vs. III }<0.001\end{array}$ \\
\hline $\operatorname{Albumin}(g / d l)$ & $\begin{array}{l}2.50 \pm 0.79 \\
M=2.30\end{array}$ & $\begin{array}{l}2.73 \pm 0.79 \\
M=2.95\end{array}$ & $\begin{array}{l}4.37 \pm 0.37 \\
M=4.30\end{array}$ & $\begin{array}{l}* 53.93 \\
<0.001(\mathrm{HS})\end{array}$ & $\begin{array}{l}\text { I vs. II =0.081 } \\
\text { I vs. III }<0.001 \\
\text { II vs. III }<0.001\end{array}$ \\
\hline$T P(g / d l)$ & $\begin{array}{l}6.19 \pm 1.20 \\
M=6.10\end{array}$ & $\begin{array}{l}6.45 \pm 1.32 \\
M=6.70\end{array}$ & $\begin{array}{l}7.41 \pm 0.41 \\
M=7.40\end{array}$ & $\begin{array}{l}8.30 \\
P=0.001(S)\end{array}$ & $\begin{array}{l}\text { I vs. II }=0.353 \\
\text { I vs. III <0.001 } \\
\text { II vs. III }=0.001\end{array}$ \\
\hline$\square-\mathbf{F P}(\mathbf{n g} / \mathbf{m l})$ & $30.20 \pm 1.35$ & $\begin{array}{l}782.85 \\
\pm 2604.23\end{array}$ & $5.44 \pm 1.79$ & $\begin{array}{l}55.48 \\
P<0.001(\mathrm{HS})\end{array}$ & $\begin{array}{l}\text { I vs. II }<0.001 \\
\text { I vs. III }=0.001 \\
\text { II vs. III }<0.001\end{array}$ \\
\hline Talin-1 (ng/ml) & $10.60 \pm 3.12$ & $32.66 \pm 12.78$ & $3.26 \pm 0.86$ & $\begin{array}{l}71.77 \\
P<0.001(H S)\end{array}$ & $\begin{array}{l}\text { I vs. II }<0.001 \\
\text { I vs. III }=0.001 \\
\text { II vs. III }<0.001\end{array}$ \\
\hline MCP1(pg/ml) & $\begin{array}{l}31.50 \pm 11.92 \\
M=30.50\end{array}$ & $\begin{array}{l}73.72 \pm 21.64 \\
M=68.75\end{array}$ & $\begin{array}{l}29.13 \pm 14.07 \\
M=28.61\end{array}$ & $\begin{array}{l}64.54 \\
P<0.001(\mathrm{HS})\end{array}$ & $\begin{array}{l}\text { I vs. II }<0.001 \\
\text { I vs. III }=0.522 \\
\text { II vs. III }<0.001\end{array}$ \\
\hline IGF1(ng/ml) & $\begin{array}{l}106.80 \pm 20.80 \\
M=107.0\end{array}$ & $\begin{array}{l}115.07 \pm 55.77 \\
M=117.0\end{array}$ & $\begin{array}{l}263.08 \pm 50.71 \\
M=262.50\end{array}$ & $\begin{array}{l}49.28 \\
P<0.001\end{array}$ & $\begin{array}{l}\text { I vs. II }=0.318 \\
\text { I vs. III }<0.001 \\
\text { II vs. III }<0.001\end{array}$ \\
\hline
\end{tabular}


Table (2): Correlation between Talin1, MCP1 and IGF1 levels and the studied parameters in HCC group:

\begin{tabular}{|c|c|c|c|c|c|c|}
\hline \multirow{3}{*}{ Parameters } & \multicolumn{6}{|c|}{$\mathrm{HCC}^{(\text {II) }}$} \\
\hline & \multicolumn{2}{|c|}{ Taline1 } & \multicolumn{2}{|c|}{ MCP1 } & \multicolumn{2}{|l|}{ IGF1 } \\
\hline & $\mathbf{r}$ & P value & $\mathbf{r}$ & P value & $\mathbf{r}$ & P value \\
\hline Taline1(ng/ml) & - & - & 0.03 & 0.817 & 0.06 & 0.712 \\
\hline MCP1 $(\mathrm{pg} / \mathrm{ml})$ & 0.03 & 0.817 & - & - & 0.54 & $<0.001(\mathrm{HS})$ \\
\hline IGF1(ng/ml) & 0.06 & 0.712 & 0.54 & $<0.001(\mathrm{HS})$ & - & - \\
\hline Age (years) & -0.15 & 0.347 & -0.08 & 0.616 & -0.18 & 0.252 \\
\hline ALT (U/L) & 0.02 & 0.863 & -0.06 & 0.709 & 0.03 & 0.821 \\
\hline $\mathbf{A S T}(\mathbf{U} / \mathbf{L})$ & 0.11 & 0.504 & -0.05 & 0.737 & -0.01 & 0.911 \\
\hline AST/ALT & 0.01 & 0.952 & 0.44 & $0.004(\mathrm{~S})$ & 0.54 & $<0.001(\mathrm{HS})$ \\
\hline$\overline{\operatorname{ALP}(\mathbf{U} / \mathbf{L})}$ & -0.13 & 0.415 & -0.10 & 0.507 & -0.12 & 0.461 \\
\hline$\square \mathbf{G T}(\mathbf{U} / \mathbf{L})$ & -0.03 & 0.821 & 0.03 & 0.858 & -0.10 & 0.517 \\
\hline Total Bilirubin (mg/dl) & 0.14 & 0.377 & -0.08 & 0.598 & 0.07 & 0.652 \\
\hline Direct Bilirubin (mg/dl) & 0.20 & 0.222 & -0.04 & 0.776 & 0.06 & 0.720 \\
\hline $\operatorname{Albumin}(\mathbf{g} / \mathbf{d l})$ & 0.01 & 0.964 & -0.10 & 0.950 & -0.54 & $<0.001(\mathrm{HS})$ \\
\hline TP $(g / d l)$ & -0.11 & 0.496 & -0.04 & 0.770 & -0.37 & 0.017 \\
\hline Pt Concentration & -0.21 & 0.182 & -0.01 & 0.946 & -0.04 & 0.809 \\
\hline INR & 0.18 & 0.258 & -0.08 & 0.621 & 0.01 & 0.921 \\
\hline$\square \mathbf{F P}(\mathbf{n g} / \mathbf{m l})$ & 0.53 & $0.006(\mathbf{S})$ & 0.28 & 0.164 & 0.23 & 0.267 \\
\hline
\end{tabular}

ROC Curve

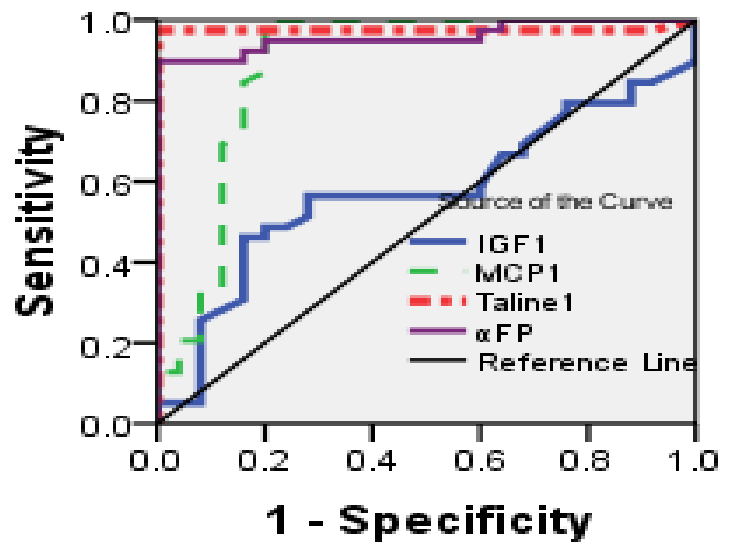

Fig 1: Roc curve for studied markers between HCC and cirrhotic

Table (3): Validity of studied markers:

\begin{tabular}{|c|c|c|c|c|c|c|c|c|c|}
\hline Marker & AUC & $\begin{array}{l}\text { Cutoff } \\
\text { point }\end{array}$ & SE & Sig & Sensitivity\% & Specificity $\%$ & PPV\% $\%$ & NPV\% & Accuracy\% \\
\hline IGF1 & 57.4 & 120.5 & 0.07 & 0.318 & 51 & 20 & 50 & 21 & 39 \\
\hline a-MCP1 & 88.9 & 52.30 & 0.05 & $<0.001$ & 100 & 80 & 89 & 100 & 92 \\
\hline b-Taline1 & 97.5 & 17.24 & 0.02 & $<0.001$ & 97 & 100 & 100 & 96 & 98 \\
\hline c- $\square$ FP & 95.9 & 4.05 & 0.02 & $<0.001$ & 95 & 80 & 88 & 91 & 89 \\
\hline \multicolumn{5}{|c|}{ Test in series (a, b \& c) } & 100 & 80 & 89 & 100 & 92 \\
\hline
\end{tabular}

Table (4): Validity of studied markers MCP1 and Taline1:

\begin{tabular}{|c|c|c|c|c|c|c|c|c|c|}
\hline Marker & AUC & $\begin{array}{l}\text { Cutoff } \\
\text { point }\end{array}$ & SE & Sig & Sensitivity $\%$ & Specificity\% & PPV\% & NPV\% & Accuracy $\%$ \\
\hline MCP1 & 88.9 & 52.30 & 0.05 & $<0.001$ & 100 & 80 & 89 & 100 & 92 \\
\hline Taline1 & 97.5 & 17.24 & 0.02 & $<0.001$ & 97 & 100 & 100 & 96 & 98 \\
\hline \multicolumn{5}{|c|}{ Test in par } & 100 & 80 & 89 & 100 & 92 \\
\hline
\end{tabular}


Table (5): Validity of studied markers Taline 1 and $\alpha \mathrm{FP}$ :

\begin{tabular}{|l|l|l|l|l|l|l|l|l|l|}
\hline Marker & AUC & $\begin{array}{l}\text { Cutoff } \\
\text { point }\end{array}$ & SE & Sig & Sensitivity\% & Specificity\% & PPV\% & NPV\% & Accuracy\% \\
\hline Taline1 & 97.5 & 17.24 & 0.02 & $<0.001$ & 97 & 100 & 100 & 96 & 98 \\
\hline$\square$ FP & 95.9 & 4.05 & 0.02 & $<0.001$ & 95 & 80 & 88 & 91 & 89 \\
\hline Test in parallel & \multicolumn{2}{|l}{} & 100 & 84 & 91 & 100 & 94 \\
\hline
\end{tabular}

Table (6): Validity of studied markers MCP1 and $\alpha$ FP:

\begin{tabular}{|l|l|l|l|l|l|l|l|l|l|}
\hline Marker & AUC & $\begin{array}{l}\text { Cutoff } \\
\text { point }\end{array}$ & SE & Sig & Sensitivity\% & Specificity\% & PPV\% & NPV\% & Accuracy\% \\
\hline MCP1 & 88.9 & 52.30 & 0.05 & $<0.001$ & 100 & 80 & 89 & 100 & 92 \\
\hline$\square$ FP & 95.9 & 4.05 & 0.02 & $<0.001$ & 95 & 80 & 88 & 91 & 89 \\
\hline Test in parallel & & 100 & 80 & 89 & 100 & 92 \\
\hline
\end{tabular}

